\title{
Effect of sulfur passivation of silicon (100) on Schottky barrier height: Surface states versus surface dipole
}

\author{
Muhammad Yusuf Alia) and Meng Tao \\ Department of Electrical Engineering, University of Texas at Arlington, Arlington, Texas 76019
}

(Received 22 August 2006; accepted 17 March 2007; published online 21 May 2007)

\begin{abstract}
Aluminum and nickel contacts were prepared by evaporation on sulfur-passivated $n$ - and $p$-type $\mathrm{Si}(100)$ substrates. The Schottky diodes were characterized by current-voltage, capacitance-voltage, and activation-energy measurements. Due to the passivation of Si dangling bonds by S, surface states are reduced to a great extent and Schottky barriers formed by $\mathrm{Al}$ and $\mathrm{Ni}$ on $\mathrm{Si}(100)$ substrates show greater sensitivity to their respective work functions. Aluminum, a low work function metal, shows a barrier height of $<0.11 \mathrm{eV}$ on $\mathrm{S}$-passivated $n$-type $\mathrm{Si}(100)$ and $\sim 0.80 \mathrm{eV}$ on $\mathrm{S}$-passivated p-type $\mathrm{Si}(100)$, as compared to 0.56 and $\sim 0.66 \mathrm{eV}$ for nonpassivated $n$ - and $p$-type $\mathrm{Si}(100)$, respectively. Nickel, a high work function metal, shows $\sim 0.72$ and $\sim 0.51 \mathrm{eV}$ on S-passivated $n$ and $p$-type $\mathrm{Si}(100)$, respectively, as compared to $\sim 0.61$ and $\sim 0.54 \mathrm{eV}$ on nonpassivated $n$ and $p$-type $\mathrm{Si}(100)$, respectively. Though a surface dipole forms due to the adsorption of $\mathrm{S}$ on $\mathrm{Si}(100)$, our experimental results indicate that the effect of surface states is the dominant factor in controlling the Schottky barrier height in these metal-Si systems. (C) 2007 American Institute of Physics.
\end{abstract}

[DOI: $10.1063 / 1.2733611]$

\section{INTRODUCTION}

The Schottky barrier height is a key parameter of any metal-semiconductor system. Ideally, for an $n$-type semiconductor, the barrier height should depend on the metal work function $\left(\phi_{m}\right)$ and semiconductor electron affinity as proposed by the Schottky-Mott theory. ${ }^{1}$ Experimentally, it is found that the barrier height is a less sensitive function of $\phi_{m}$ and under certain circumstances, the barrier height is almost independent of the choice of metal. This is evident from the study of Mead and Spitzer. ${ }^{2}$ The weak dependence of the Schottky barrier height on metal work function was attributed to the high density of surface or interface states between the metal and semiconductor, ${ }^{3}$ which effectively pin the interface Fermi level, making the barrier height deviate from the Schottky-Mott theory. Surface states originate from the termination of the periodic structure of a semiconductor crystal at the surface. ${ }^{4}$ Kaxiras $^{5}$ was the first to propose the "valence-mending" concept to passivate dangling bonds on semiconductor surfaces and to consider its application to the $\mathrm{Si}(100)$ surface. According to his criteria, selenium (Se) and sulfur (S) from Group VI in the periodic table are proper valence-mending adsorbates to terminate the dangling bonds on $\mathrm{Si}(100)$. Theoretical ${ }^{5,6}$ and experimental ${ }^{7-9}$ results showed that $\mathrm{S}$ or $\mathrm{Se}$ atoms are adsorbed in a bridge position on $\mathrm{Si}(100)$. Tao et al. ${ }^{10,11}$ demonstrated that by passivating the $\mathrm{Si}(100)$ surface with a monolayer of Se, the dangling bonds can be removed and nearly ideal Schottky barrier heights can be achieved using different metals. Use of a $\mathrm{S}$ or Secontaining solution is widespread for the passivation of the GaAs(100) surface. $^{12-15}$ Solutions containing ammonium sulfide $\left[\left(\mathrm{NH}_{4}\right)_{2} \mathrm{~S}\right]$ have also been used to passivate $\mathrm{Ge}(100)$ (Ref. 16) and InP(100) (Ref. 17) substrates.

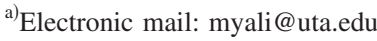

In this paper we report the effect of $S$ passivation of the $\mathrm{Si}(100)$ surface on the Schottky barrier height using low and high work function metals, i.e., aluminum (Al) and nickel (Ni), respectively. Due to the passivation of $\mathrm{Si}$ dangling bonds by $\mathrm{S}$, surface states are reduced to a great extent and Schottky barriers formed by $\mathrm{Al}$ and $\mathrm{Ni}$ on $\mathrm{Si}(100)$ substrates show greater sensitivity to their respective work functions. Though a surface dipole forms due to the adsorption of $\mathrm{S}$ on $\mathrm{Si}(100)$, our experimental results indicate that the effect of surface states is the dominant factor in controlling the Schottky barrier height in these metal-Si systems.

\section{EXPERIMENTAL}

$\operatorname{Si}(100)$ wafers of both $n$ - and $p$-type were used for the experiments. The $n$-type wafers were doped with arsenic and the $p$-type with boron, both in the low $10^{15} \mathrm{~cm}^{-3}$ range. The nominal wafer miscut was less than $0.5^{\circ}$. One set of the wafers was $\mathrm{S}$ passivated while the other set had no $\mathrm{S}$ passivation for a comparison purpose. For the S-passivated samples, the wafers were first cleaned with $2 \%$ hydrofluoric acid (HF) for $30 \mathrm{~s}$. The wafers were then passivated with $\mathrm{S}$ in a solution containing $\left(\mathrm{NH}_{4}\right)_{2} \mathrm{~S}$. A $700 \AA$ Al layer was deposited by thermal evaporation on one set of the passivated wafers (both the $n$ - and $p$-type). On another set of the passivated wafers (both the $n$ - and $p$-type), a $700 \AA \mathrm{Ni}$ layer was deposited in the same manner. All the wafers were then patterned using a lift-off technique. The contact size was 100, 200 , and $300 \mu \mathrm{m}$ in diameter. For the set of wafers without $\mathrm{S}$ passivation, they were cleaned with $2 \% \mathrm{HF}$ for $30 \mathrm{~s}$ only and then $\mathrm{Al}$ and $\mathrm{Ni}$ were deposited and patterned in the same manner as the passivated samples. Aluminum was deposited on the backside of all the wafers for back ohmic contact. The larger area of the back contact compared to the front contacts $\left(>10^{5}\right.$ times larger) made possible characterization of the 


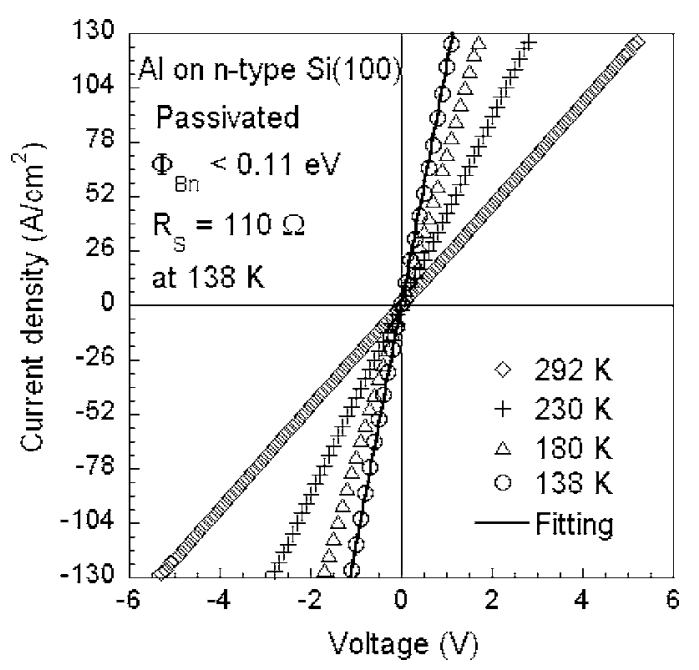

FIG. 1. $I-V$ characteristics of two back-to-back Schottky diodes with Al on S-passivated $n$-type $\mathrm{Si}(100)$ at different temperatures. Solid line shows the fitting result with the thermionic-emission model for data at $138 \mathrm{~K}$.

front diodes with negligible effect of the Schottky behavior from the back contact. The front Schottky diodes were characterized by current-voltage $(I-V)$, capacitance-voltage $(C-V)$, and activation-energy measurements.

\section{RESULTS AND DISCUSSION}

\section{A. I- V measurements}

Figure 1 shows the $I-V$ characteristics of two back-toback Schottky diodes with $\mathrm{Al}$ on $\mathrm{S}$-passivated $n$-type $\mathrm{Si}(100)$ at different temperatures. The $I-V$ characteristics are linear at temperatures as low as $138 \mathrm{~K}$, the lowest achievable temperature in our laboratory. With this linear $I-V$ characteristics, $C-V$ and activation-energy methods fail to yield a barrier height. It should be noted that the Schottky characteristics of a very low Schottky barrier can be overshadowed by a high series resistance. In such cases, the barrier height can be determined with low-temperature $I-V$ measurements. ${ }^{18}$ According to the thermionic-emission model, the $I-V$ relation for a Schottky diode is given by ${ }^{1}$

$$
I=A A^{* *} T^{2} e^{-\phi_{B}(q / k T)}\left(e^{(q / n k T)(V-I R)}-1\right),
$$

where $A$ is the area of the contact, $A^{* *}$ is the effective Richardson constant, $T$ is the temperature, $k$ is the Boltzmann constant, $q$ is the electron charge, $\phi_{B}$ is the Schottky barrier height, $n$ is the ideality factor, $V$ is the applied voltage, and $R$ is the series resistance. A simple-minded fitting of the thermionic-emission model to the low-temperature data at $138 \mathrm{~K}$, shown as a solid line in Fig. 1, suggests that the barrier height is no more than $0.11 \mathrm{eV}$. This value agrees well with the barrier height measured for Al on Se-passivated $n$-type $\operatorname{Si}(100){ }^{11}$

Figure 2 shows the $I-V$ characteristics of Schottky diodes with $\mathrm{Al}$ on $n$ - and $p$-type $\mathrm{Si}(100)$ at room temperature. Sulfur passivation reduces the reverse saturation current by more than an order of magnitude for $\mathrm{Al} / p$-type $\mathrm{Si}(100)$ diodes, implying that $\mathrm{S}$ passivation increases the barrier height

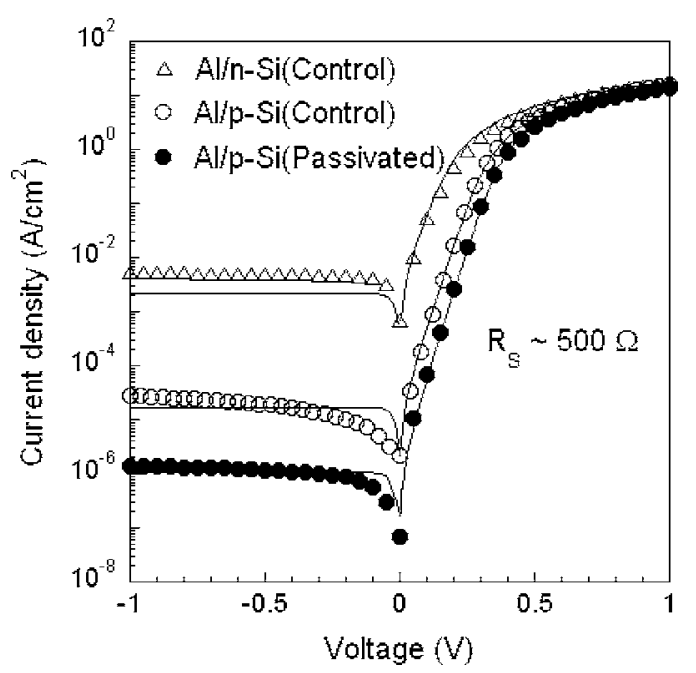

FIG. 2. $I-V$ characteristics of $\mathrm{Al}$ on $n$ - and $p$-type $\mathrm{Si}(100)$ at room temperature. Solid lines are the fitting results with the thermionic-emission model for corresponding experimental data.

for $\mathrm{Al} / p$-type $\mathrm{Si}(100)$ contacts. This observation is quantitatively verified by activation-energy and $C-V$ measurements, as discussed later.

Figure 3 shows the $I-V$ characteristics of Schottky diodes with $\mathrm{Ni}$ on $n$ - and $p$-type $\mathrm{Si}(100)$ at room temperature. Sulfur passivation reduces the reverse saturation current by more than an order of magnitude for $\mathrm{Ni} / n$-type $\mathrm{Si}(100)$ diodes, while it doubles the reverse current for $\mathrm{Ni} / p$-type $\mathrm{Si}(100)$ diodes. In both Figs. 2 and 3, it is noticed that the forward current does not appear linear in the logarithmic plots, indicating that the forward current is limited by a high series resistance $(\sim 500 \Omega)$ in all the samples. The $I-V$ characteristics in Figs. 2 and 3 were fitted with the thermionicemission model as shown by the solid lines in those figures. The fittings allowed the extraction of the barrier height and ideality factor, which are listed in Table I under the column labeled $I-V$. As can be seen from the table, $\mathrm{S}$ passivation increases the barrier height by $\sim 0.12 \mathrm{eV}$ for $\mathrm{Ni} / n$-type $\mathrm{Si}(100)$ contacts and decreases the barrier height by

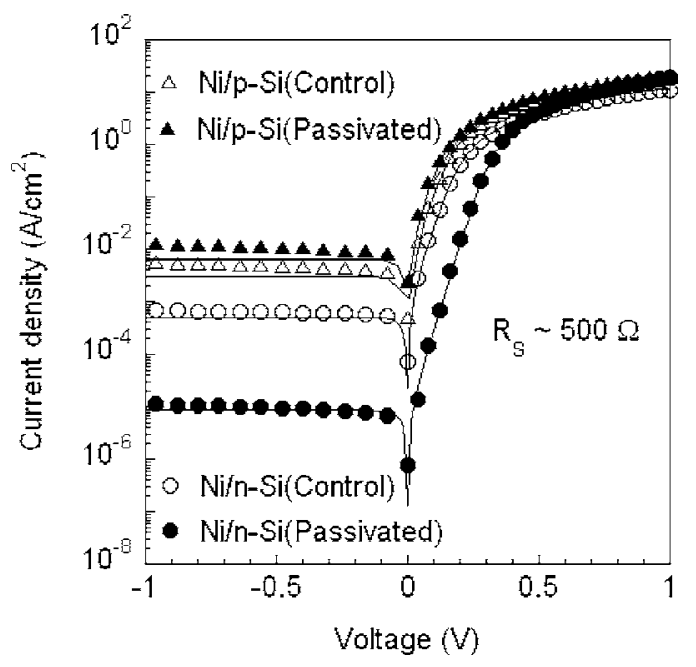

FIG. 3. $I-V$ characteristics of $\mathrm{Ni}$ on $n$ - and $p$-type $\mathrm{Si}(100)$ at room temperature. Solid lines are the fitting results with the thermionic-emission model for corresponding experimental data. 
TABLE I. Summary of the measured Schottky barrier height and ideality factor on both $\mathrm{S}$-passivated $\mathrm{Si}(100)$ and nonpassivated $\mathrm{Si}(100)$ (unit: $\mathrm{eV}$ ).

\begin{tabular}{lcrccccc}
\hline \hline Metal & Type & $\begin{array}{c}\text { Ideal } \\
\text { barrier }\end{array}$ & Sample type & $n$ & $I-V$ & $\begin{array}{c}\text { Activation } \\
\text { energy }\end{array}$ & $C-V$ \\
\hline $\mathrm{Al}$ & $n$ & -0.01 & Control & 1.2 & 0.56 & - & - \\
$\mathrm{Al}$ & $n$ & -0.01 & Passivated & - & $<0.11$ & - & - \\
$\mathrm{Al}$ & $p$ & 1.13 & Control & 1.15 & 0.65 & 0.66 & 0.67 \\
$\mathrm{Al}$ & $p$ & 1.13 & Passivated & 1.08 & 0.71 & 0.78 & 0.80 \\
$\mathrm{Ni}$ & $n$ & 0.86 & Control & 1.08 & 0.59 & 0.61 & 0.62 \\
$\mathrm{Ni}$ & $n$ & 0.86 & Passivated & 1.02 & 0.70 & 0.72 & 0.75 \\
$\mathrm{Ni}$ & $p$ & 0.26 & Control & 1.10 & 0.52 & 0.53 & 0.56 \\
$\mathrm{Ni}$ & $p$ & 0.26 & Passivated & 1.03 & 0.50 & 0.51 & 0.52 \\
\hline \hline
\end{tabular}

$\sim 0.03 \mathrm{eV}$ for $\mathrm{Ni} / p$-type $\mathrm{Si}(100)$ contacts. The changes in barrier height are reflected in the reverse saturation currents measured.

\section{B. Activation-energy and $C-V$ measurements}

In our activation-energy measurements, the barrier height is determined from the temperature-dependent reverse saturation current $\left(I_{S}\right)$. A plot of $\ln \left(I_{S} / T^{2}\right)$ versus $1 / T$ gives a straight line and the barrier height is calculated from the slope $^{19}$

$$
\text { Slope }=-\frac{q}{k} \phi_{B}
$$

The advantage of this method is that, with a sufficiently large reverse voltage, the effect of the high series resistance can be minimized. In $C-V$ measurements, the intercept of a $1 / C^{2}$ versus $V$ plot gives the amount of surface band bending and the barrier height can be calculated as ${ }^{20}$

$$
\phi_{B}=V_{i}+V_{n}+\frac{k T}{q}-\Delta \phi,
$$

where $V_{i}$ is the intercept on the voltage axis from the $1 / C^{2}$ versus $V$ plot, $V_{n}$ is the difference between the conduction band and Fermi level for $n$-type $\mathrm{Si}(100)$ and for $p$-type $\mathrm{Si}(100), V_{n}$ is the difference between the valence band and Fermi level, and $\Delta \phi$ is the amount of Schottky barrier lowering due to the image force.

Figure 4(a) shows an activation-energy plot and Fig. 4(b) shows a $1 / C^{2}$ versus $V$ plot of $\mathrm{Al}$ on both $\mathrm{S}$-passivated and nonpassivated $p$-type $\mathrm{Si}(100)$. Two back-to-back Schottky diodes were used for the measurement of the reverse saturation current. ${ }^{18}$ The $C-V$ measurement was performed at 1 $\mathrm{MHz}$ and the extracted doping concentration is $\sim 2$ $\times 10^{15} \mathrm{~cm}^{-3}$, in agreement with the wafer specification. The maximum Schottky barrier lowering $(\Delta \phi)$ is estimated at $\sim 0.01 \mathrm{eV}$ and is not included in the analysis. Both $C-V$ and activation-energy measurements reveal that $\mathrm{S}$ passivation increases the barrier height by $\sim 0.13 \mathrm{eV}$ for $\mathrm{Al} / p$-type $\mathrm{Si}(100)$ contacts.

Figure 5(a) shows an activation-energy plot and Fig. 5(b) shows a $1 / C^{2}$ versus $V$ plot of $\mathrm{Ni}$ on both $\mathrm{S}$-passivated and nonpassivated $n$-type $\mathrm{Si}(100)$. Sulfur passivation increases the barrier height by $\sim 0.12 \mathrm{eV}$ for $\mathrm{Ni} / n$-type $\mathrm{Si}(100)$ contacts, which supports the $I-V$ measurement discussed above.
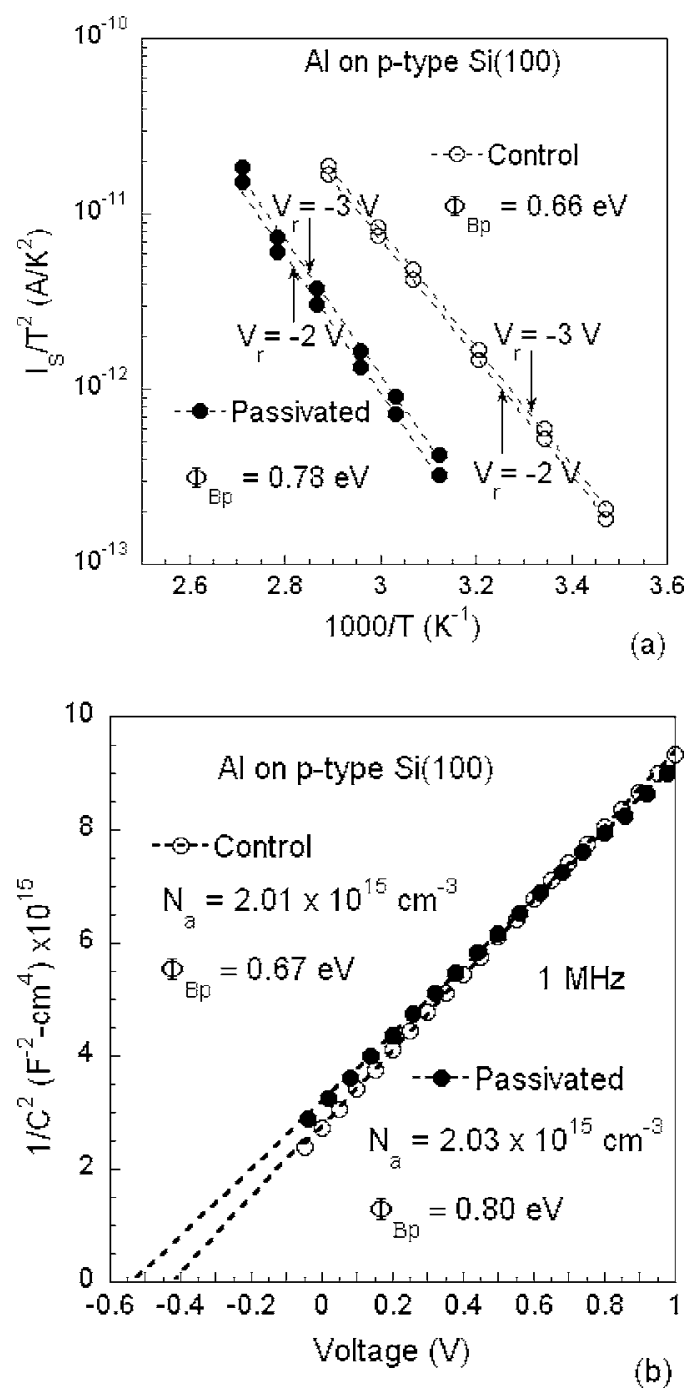

FIG. 4. Determination of Schottky barrier height between Al and p-type $\mathrm{Si}(100)$ from (a) activation-energy measurement, (b) $C-V$ measurement for both S-passivated and nonpassivated samples.

Figure 6(a) shows an activation-energy plot and Fig. 6(b) shows a $1 / C^{2}$ versus $V$ plot of $\mathrm{Ni}$ on both $\mathrm{S}$-passivated and nonpassivated $p$-type $\mathrm{Si}(100)$. In this case, $\mathrm{S}$ passivation reduces the barrier height by $\sim 0.03 \mathrm{eV}$ for $\mathrm{Ni} / p$-type $\mathrm{Si}(100)$ contacts and thus doubles the reverse current as found in the $I-V$ measurement. The doping concentration found from $C-V$ for the control sample is $\sim 6 \times 10^{14} \mathrm{~cm}^{-3}$, which is lower as compared to other samples. In Figs. 5(b) and 6(b), there is a slope change between control and S-passivated samples. We speculate that different doping concentrations in the wafers may be the cause for the slope change.

The effective Richardson constant $A^{* *}$ can be extracted from the activation-energy plots in Figs. 4-6. Its values for electrons are $\sim 669$ and $\sim 580 \mathrm{~A} / \mathrm{cm}^{2} \mathrm{~K}^{2}$ for control and $\mathrm{S}$-passivated samples, respectively. The values of $A^{* *}$ for holes are $\sim 130$ and $\sim 195 \mathrm{~A} / \mathrm{cm}^{2} \mathrm{~K}^{2}$ for control and S-passivated samples, respectively. The difference in effective Richardson constant between control and S-passivated samples is marginal, considering the fact that Richardson constant depends on several surface factors such as surface preparation and cleaning procedure. $^{21}$ 


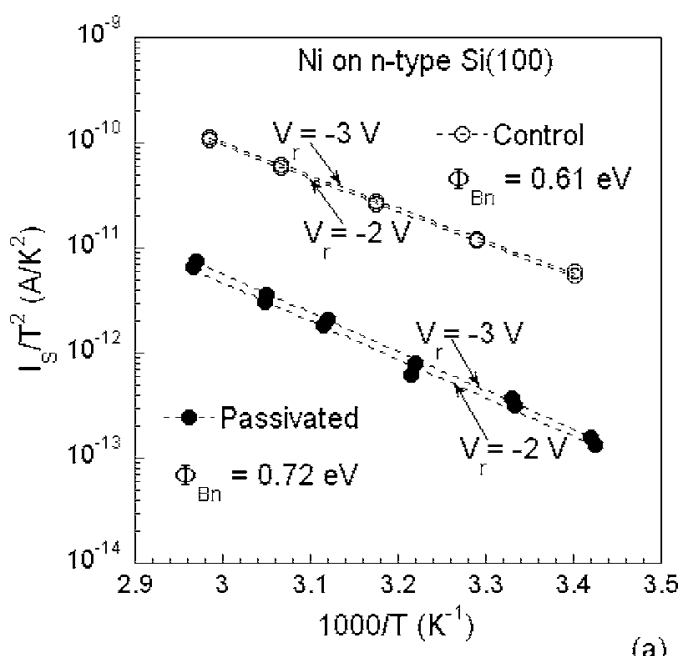

(a)

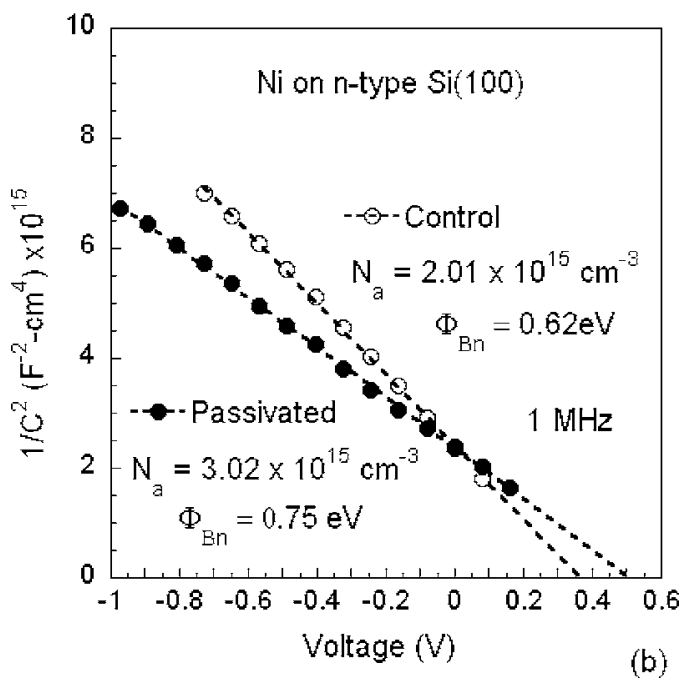

FIG. 5. Determination of Schottky barrier height between Ni and $n$-type $\mathrm{Si}(100)$ from (a) activation-energy measurement, (b) $C-V$ measurement for both S-passivated and nonpassivated samples.

\section{Summary of measurements}

Table I provides a summary of the measured barrier height and ideality factor for these Schottky diodes using different methods. It also lists the ideal barrier heights for $\mathrm{Al}$ and $\mathrm{Ni}$ for a comparison purpose. In calculating the ideal barrier heights, the electron affinity of $\mathrm{Si}$ is taken as $4.29 \mathrm{eV}$ (Refs. 11 and 22) and the work functions of $\mathrm{Al}$ and $\mathrm{Ni}$ are taken as 4.28 and $5.15 \mathrm{eV}$, respectively. ${ }^{22}$ The ideal barrier height for $\mathrm{Al}$ on $n$-type $\mathrm{Si}(100)$ is $-0.01 \mathrm{eV}$, and the ideal barrier height for $\mathrm{Al}$ on $p$-type $\mathrm{Si}(100)$ is $1.13 \mathrm{eV}$. This means that the conduction band bends down and crosses the Fermi level causing degeneracy at the $\mathrm{Al} / \mathrm{Si}(100)$ interface. ${ }^{11}$ Table II shows the band gap values of Si by adding the measured barrier heights of $\mathrm{Ni}$ on $n$ - and $p$-type $\mathrm{Si}(100){ }^{20}$ Control samples provide a better agreement for the band gap of $\mathrm{Si}(1.12 \mathrm{eV})$ than passivated samples. The worst case is for $\mathrm{Al}$ on S-passivated $\mathrm{Si}(100)$. The measured barrier heights on the $n$ - and $p$-type add up to a maximum of $0.91 \mathrm{eV}$, which is $0.2 \mathrm{eV}$ below the band gap of $\mathrm{Si}$. It is speculated that wet-chemical passivation cannot guarantee perfect monolayer passivation. Incomplete passivation of the $\mathrm{Si}(100)$ sur-
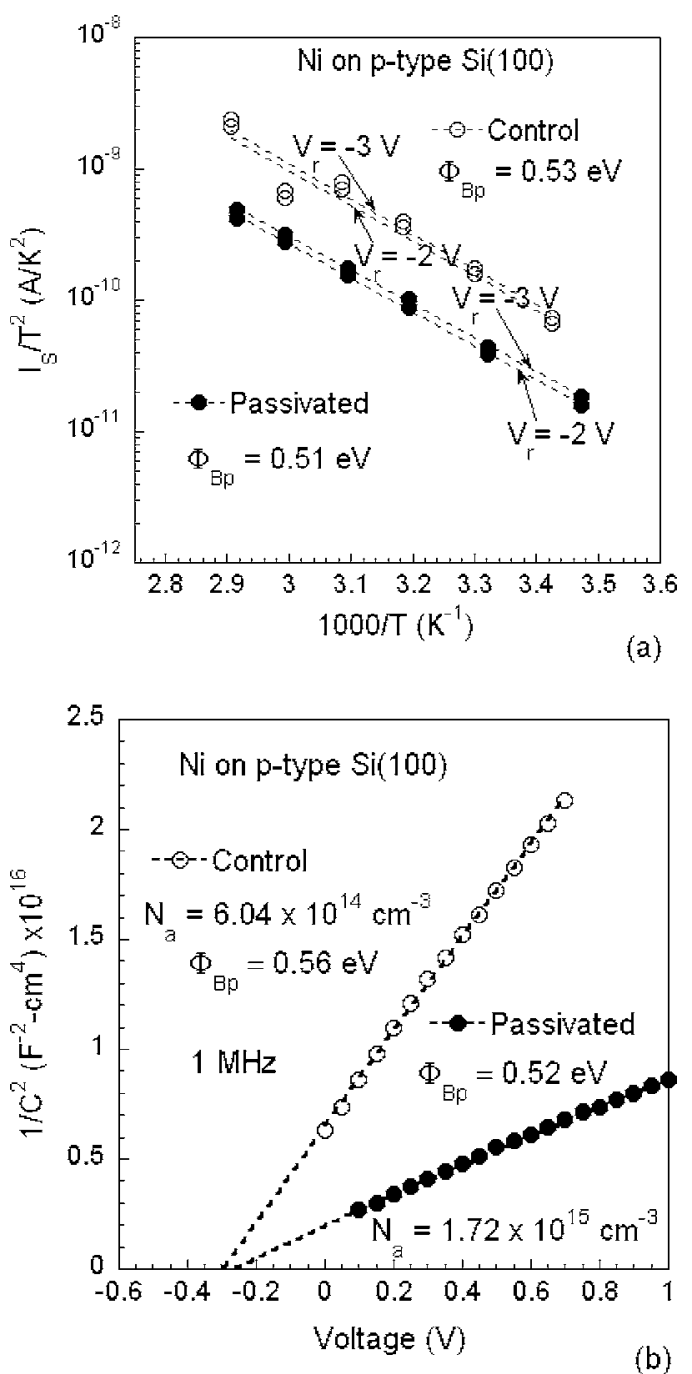

(b)

FIG. 6. Determination of Schottky barrier height between Ni and p-type $\mathrm{Si}$ (100) from (a) activation-energy measurement, (b) $C-V$ measurement for both S-passivated and nonpassivated samples.

face leaves nonpassivated regions where the Schottky barrier height is determined by the pinned interface Fermi level. The effect of incomplete passivation is particularly prominent with a high barrier, such as $\mathrm{Al} / p$-type $\mathrm{Si}(100)$ contacts, where the difference in the barrier height between passivated regions and nonpassivated regions is high. The measured barrier height on such a sample should be much lower than the ideal barrier height.

\section{Surface states versus surface dipole}

The changes in barrier height due to S passivation may be attributed to two factors. One is the reduction of surface

TABLE II. Band gap values of Si by adding the measured barrier heights for Ni on $n$ - and $p$-type $\mathrm{Si}(100)$ (unit: eV).

\begin{tabular}{cccc}
\hline \hline Sample type & $I-V$ & $\begin{array}{c}\text { Activation } \\
\text { energy }\end{array}$ & $C-V$ \\
\hline $\mathrm{Ni} / \mathrm{Si}$ & 1.11 & 1.14 & 1.18 \\
$\mathrm{Ni} / \mathrm{S} / \mathrm{Si}$ & 1.2 & 1.23 & 1.27 \\
\hline \hline
\end{tabular}


states due to the passivation of dangling bonds, and the other is the S-induced surface dipole. An interesting question is, which factor is the dominant one? With the choices of metal with different work functions, Al with a low work function $(4.28 \mathrm{eV})$ and $\mathrm{Ni}$ with a high work function $(5.15 \mathrm{eV})$, our results provide an answer to the question.

Following the surface-state theory, in the absence of surface states, the Schottky barrier height depends solely on the metal work function and semiconductor electron affinity. The density of surface states can be estimated by the procedure developed by Cowley and Sze. ${ }^{4}$ With their procedure, we calculated the density of surface states for the S-passivated $\operatorname{Si}(100)$ surface and it turned out to be $\sim 3.86 \times 10^{12} \mathrm{~cm}^{-2}$, while for the nonpassivated $\operatorname{Si}(100)$ surface, it was $\sim 9.9$ $\times 10^{13} \mathrm{~cm}^{-2}$. Therefore, $\mathrm{S}$ passivation reduces the density of surface states on $\mathrm{Si}(100)$ by more than an order of magnitude. Carpenter et al. ${ }^{13}$ have found similar improvement with $\mathrm{S}$ passivation of the $\mathrm{GaAs}(100)$ surface.

The change in barrier height due to adsorbate-induced surface dipole can be expressed as ${ }^{23}$

$$
\Delta \phi_{B}=\left(\frac{q}{\varepsilon_{o} \varepsilon_{i}}\right) \mu_{o} N_{\mathrm{ad}},
$$

where $\varepsilon_{o}$ and $\varepsilon_{i}$ are the permittivity of vacuum and interface layer, respectively, $\mu_{o}$ is the dipole moment, and $N_{\mathrm{ad}}$ is the number of adsorbed atoms per unit surface area. $N_{\mathrm{ad}}$ is $6.78 \times 10^{14} \mathrm{~cm}^{-2}$ for a perfectly passivated $\mathrm{Si}(100)$ surface. $\varepsilon_{i}$ is often taken as $4.0 .^{23-25}$ For the Si-S system, the dipole moment was experimentally found to be 0.2 Debye for a monolayer coverage by Papageorgopoulos et al. ${ }^{26}$ Using these values, the barrier height change $\left(\Delta \phi_{B}\right)$ is $\sim 0.13 \mathrm{eV}$ for perfect one monolayer $\mathrm{S}$ coverage. Although the ultrahigh vacuum data from Papageorgopoulos may not be applicable to our solution-passivated samples and thus the exact value of barrier height change may be arguable, the key point is that the change in barrier height due to surface dipole is always unidirectional. For the $\mathrm{Si}-\mathrm{S}$ system, the surface dipole will always decrease the barrier height on $n$-type $\mathrm{Si}(100)$ and increase the barrier height on $p$-type $\mathrm{Si}(100) .^{23}$ This is in contrary to our experiments in which $\mathrm{S}$ passivation decreases the barrier height for $\mathrm{Ni}$ on $p$-type $\mathrm{Si}(100)$ and increases the barrier height for $\mathrm{Ni}$ on $n$-type $\mathrm{Si}(100)$. However, these results are expected from the surface-state theory, i.e., depending on the work function of metal, the change in barrier height can go in both directions when surface states are passivated. These experimental findings suggest that surface dipole plays a less significant role than surface states in determining the Schottky barrier height in these metal-Si systems.

\section{CONCLUSION}

The effect of $\mathrm{S}$ passivation of the $\mathrm{Si}(100)$ surface, both $n$ - and $p$-type, on the Schottky barrier height has been investigated with low and high work function metals, $\mathrm{Al}$ and $\mathrm{Ni}$, respectively. It is found that $\mathrm{S}$ passivation of $\mathrm{Si}(100)$ reduces the density of surface states by more than an order of magnitude. This reduction in surface-state density results in changes in the Schottky barrier height, which are more sensitive to the work function of the chosen metal. Aluminum, a low work function metal, shows a barrier height of $<0.11 \mathrm{eV}$ on S-passivated $n$-type $\mathrm{Si}(100)$ and $\sim 0.80 \mathrm{eV}$ on $\mathrm{S}$-passivated $p$-type $\mathrm{Si}(100)$, as compared to 0.56 and $\sim 0.66 \mathrm{eV}$ for nonpassivated $n$ - and $p$-type $\mathrm{Si}(100)$, respectively. Nickel, a high work function metal, shows $\sim 0.72$ and $\sim 0.51 \mathrm{eV}$ on $\mathrm{S}$-passivated $n$ - and $p$-type $\mathrm{Si}(100)$, respectively, as compared to $\sim 0.61$ and $\sim 0.54 \mathrm{eV}$ on nonpassivated $n$ - and $p$-type $\mathrm{Si}(100)$, respectively. Our experimental results suggest that surface states play the dominant role over surface dipole in controlling the Schottky barrier height in these metal-Si systems.

\section{ACKNOWLEDGMENTS}

This project was supported by the National Science Foundation under Grant Nos. 0322762 and 0620319 and the Texas Advanced Technology Program under Grant No. 003656-0096.

${ }^{1}$ E. H. Rhoderick and R. H. Williams, Metal-Semiconductor Contacts, 2nd ed. (Oxford, New York, 1988).

${ }^{2}$ C. A. Mead and W. G. Spitzer, Phys. Rev. 134, A713 (1964).

${ }^{3}$ J. Bardeen, Phys. Rev. 71, 717 (1947).

${ }^{4}$ A. M. Cowley and S. M. Sze, J. Appl. Phys. 36, 3212 (1965).

${ }^{5}$ E. Kaxiras, Phys. Rev. B 43, 6824 (1991).

${ }^{6}$ P. Krüger and J. Pollmann, Phys. Rev. B 47, 1898 (1993).

${ }^{7}$ A. Papageorgopoulos and M. Kamaratos, Surf. Sci. 352-354, 364 (1996).

${ }^{8}$ A. C. Papageorgopoulos and M. Kamaratos, Surf. Sci. 466, 173 (2000).

${ }^{9}$ J. P. Lacharme, N. Benazzi, and C. A. Sebenne, Surf. Sci. 433-435, 415 (1999).

${ }^{10}$ M. Tao, D. Udeshi, N. Basit, E. Maldonado, and W. P. Kirk, Appl. Phys. Lett. 82, 1559 (2003).

${ }^{11}$ M. Tao, S. Agarwal, D. Udeshi, N. Basit, E. Maldonado, and W. P. Kirk, Appl. Phys. Lett. 83, 2593 (2003).

${ }^{12}$ C. J. Sandroff, R. N. Nottenburg, J. C. Bischoff, and R. Bhat, Appl. Phys. Lett. 51, 33 (1987).

${ }^{13}$ M. S. Carpenter, M. R. Melloch, and T. E. Dungan, Appl. Phys. Lett. 53, 66 (1988).

${ }^{14}$ C. J. Sandroff, M. S. Hegde, L. A. Farrow, R. Bhat, J. P. Harbison, and C. C. Chang, J. Appl. Phys. 67, 586 (1990).

${ }^{15}$ Y. Wang, Y. Darici, and P. H. Holloway, J. Appl. Phys. 71, 2746 (1992).

${ }^{16}$ G. W. Anderson, M. C. Hanf, P. R. Norton, Z. H. Lu, and M. J. Graham, Appl. Phys. Lett. 66, 1123 (1995).

${ }^{17}$ Y. Tao, A. Yelon, E. Sacher, Z. H. Lu, and M. J. Graham, Appl. Phys. Lett. 60, 2669 (1992).

${ }^{18}$ E. Dubois and G. Larrieu, J. Appl. Phys. 96, 729 (2004).

${ }^{19}$ K. Chino, Solid-State Electron. 16, 119 (1973).

${ }^{20}$ S. M. Sze, Physics of Semiconductor Devices, 2nd ed. (Wiley, New York, 1981).

${ }^{21}$ N. T. Tam and T. Chot, Phys. Status Solidi A 93, K91 (1986).

${ }^{22}$ H. B. Michaelson, J. Appl. Phys. 48, 4729 (1977).

${ }^{23}$ T. U. Kampen and W. Monch, Surf. Sci. 331-333, 490 (1995).

${ }^{24}$ R. Ludeke, G. Jezequel, and A. Taleb-Ibrahimi, Phys. Rev. Lett. 61, 601 (1988).

${ }^{25}$ P. K. W. Vinsome and D. Richardson, J. Phys. C 4, 2650 (1971).

${ }^{26}$ A. Papageorgopoulos, A. Corner, M. Kamaratos, and C. A. Papageorgopoulos, Phys. Rev. B 55, 4435 (1997). 